\title{
Morpho-textural changes of the patellar tendon in professional volleyball players: a six month longitudinal study
}

\author{
de Groot Ferrando A. ${ }^{1}$ \\ ${ }^{1}$ Clínica Campos, Alicante, Spain \\ Rev Fisioter Invasiva 2019;2:126.
}

\begin{abstract}
Introduction Tendinopathy is a term used to describe a clinical presentation of pain and dysfunction, which, at times, is accompanied by pathologic structural changes in the tendon matrix. Jumper's knee has been studied for some time, however the etiology is still unknown. The deep fibers of the proximal region are the most affected area in tendinopathies affecting the patellar tendon. Ultrasound (US) scanning may have the greatest sensitivity for confirming clinically diagnosed patellar tendinopathy compared with other imaging techniques such as magnetic resonance. Some studies have found that a minimum of six months is required to observe significant structural changes, although other studies reveal that structural changes can be visible in a shorter period of time. Thus, sonography has been used to evaluate quantitative variables such as thickness, echogenicity, texture measures and the internal tendon matrix.

Objective The purpose of this study was to evaluate the sonographic behavior of morpho-textural changes of the patellar tendon in professional male volleyball players over a one year season.

Material and Methods This is an observational, longitudinal and analytical study. A sample of 66 patellar tendons from 33 volleyball players of the Spanish super league was recruited, with an average of: 28 years, $86 \mathrm{~kg}$ and $192 \mathrm{~cm}$. An ultrasound scan was performed using the Sonosite Titan ultrasound system, $\mathrm{L} 38,5-10 \mathrm{MHz}$, with a cross section of $5 \mathrm{~mm}$ from the lower pole of the patella. Two depths were analyzed: a.39mm: echogenicity, echogenicity variation, circularity, width and thickness. b. $24 \mathrm{~mm}$ : entropy and contrast. Statistical analysis and analysis of variance (ANOVA) was performed for repeated measures and, in addition, the effect size was calculated with Cohen's $d$. The confidence interval was $95 \%$. SPSS Statistics software was used.

Results For textural variables: contrast increased significantly with an average effect size, and entropy showed no significant difference. Circularity was significantly lower. Width was shown to be significantly greater, with an average effect size, while thickness was reduced significantly. Regarding echogenicity, no significant changes were detected and variation in echogenicity did not show significant changes.

\section{Keywords}

- ultrasound

- volleyball

- patellar tendon

- computer assisted image analysis

Conclusions Imaging analysis could be a potential tool to detect changes in the pattern of patellar tendons. Some morpho-textural changes were found in male volleyball players: the textural contrast variable increases significantly throughout the annual season, meaning that the tendon becomes slightly flatter and loses circularity in its transverse section. The entropy and echogenic parameters obtained from the gray-scale histogram did not reveal any significant changes.
\end{abstract}

DOI https://doi.org/ 10.1055/s-0039-3402505. ISSN 2386-4591.
Copyright $\odot 2019$ by Thieme Revinter Publicações Ltda, Rio de Janeiro, Brazil
License terms

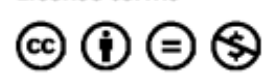

